\title{
Low Back Pain Prevalence and Associated Factors in Iranian Population: Findings from the National Health Survey
}

\author{
Akbar Biglarian, ${ }^{1}$ Behjat Seifi, ${ }^{2}$ Enayatollah Bakhshi, ${ }^{3}$ Kazem Mohammad, ${ }^{4}$ \\ Mehdi Rahgozar, ${ }^{3}$ Masoud Karimlou, ${ }^{3}$ and Sara Serahati ${ }^{5}$ \\ ${ }^{1}$ Pediatric Neurorehabilitation Research Center, University of Social Welfare and Rehabilitation Sciences, Tehran, Iran \\ ${ }^{2}$ Department of Physiology, Medicine School, Tehran University of Medical Sciences, Tehran, Iran \\ ${ }^{3}$ Department of Biostatistics, University of Social Welfare and Rehabilitation Sciences, Tehran, Iran \\ ${ }^{4}$ Department of Biostatistics, School of Public Health and Institute of Public Health Research, \\ Tehran University of Medical Sciences, Tehran, Iran \\ ${ }^{5}$ Student Research Committee, University of Social Welfare and Rehabilitation Sciences, Tehran, Iran
}

Correspondence should be addressed to Enayatollah Bakhshi, bakhshi@razi.tums.ac.ir

Received 19 June 2012; Accepted 1 August 2012

Academic Editor: Jeffrey J. Borckardt

Copyright ( 2012 Akbar Biglarian et al. This is an open access article distributed under the Creative Commons Attribution License, which permits unrestricted use, distribution, and reproduction in any medium, provided the original work is properly cited.

\begin{abstract}
Background. There are very few studies that had a sample size sufficient to explore the association between factors related to low back pain in a representative sample of the Iranian population. Objective. To examine the relationship between sociodemographic factors, smoking, obesity, and low back pain in Iranian people. Methods. We used Iranian adults respondents $(n=25307)$ from the National Health Survey. Adjusted odds ratios and 95\% confidence intervals were estimated by using logistic regression. Results. The prevalence of low back pain was found in $29.3 \%$ of the studied sample. High age, female sex, being married, obesity, low-economic index, being smoker, in a rural residence, and low educational attainment, all increased the odds of low back pain. Conclusions. Our findings add to the evidence on the importance of obesity in relation to low back pain. These results can be used as a basis to reinforce health programs to prevent obesity.
\end{abstract}

\section{Introduction}

Low back pain (LBP) is a common medical problem $[1,2]$ that has many outcomes including disability [3] and taking time off from work $[3,4]$. LBP is a major public health problem in the USA because more than 34 million (17\%) adults reported LBP only, and 19 million (9\%) reported LBP and neck pain in a 3 months duration [1]. One study in Canada estimated that $84 \%$ of adults have had LBP during their lifetime [5]. Average prevalences were 59\% in UK [6], $70 \%$ in Denmark [7], and 75\% in Finland [8]. In the general population, the prevalence of low back pain in a 1-month and annual duration ranges from $30 \%$ to $40 \%$ and $25 \%$ to $60 \%$, respectively [9-11].

Overweight and obesity are also public health problems, due to their rapid growth in recent decades and their related health disorders, such as cardiovascular diseases, diabetes, some cancers, and other diseases [12]. In recent years, the statistics about obesity were appalling. In 2010, almost 43 million children (35 million in developing countries and 8 million in developed countries) were estimated to be overweight or obese [13]. It has been estimated that by 2020, type 2 diabetes and cardiovascular disease will account for almost $75 \%$ of all deaths worldwide [14].

Because of multifactorial nature of LBP, researchers have focused on both medical and nonmedical factors such as sociodemographic factors [15-18]. One potential predictor could be age. The positive association between age and LBP has been found in some studies $[19,20]$. Another predictor is sex which has shown that LBP is more common in female than in male [2, 10, 21-24]. Bener et al. found a statistically significant association between place of residence and LBP among patients attending primary health care [19]. Some studies have shown that smoking is consistently associated 
with LBP [7, 25-28]. Findings from some studies showed that people with low levels of educational and low income have had the higher prevalence of LBP [3, 26-29].

Although obesity is a significant factor that is frequently associated with the presence of LBP $[1,30-32]$, but this association has not been confirmed by other studies $[33,34]$. In a meta-analysis, Shiri et al. [24]. reported that obesity increases the risk of LBP [24]. Their findings showed that this association is stronger women than men.

Until now very few studies of the association between factors related to LBP have been carried out in a representative sample of Iranian population. Therefore, it is clear that there is a need to determine the factors related to LBP of people in this country. The present study was designed to assess relationships between age, sex, education level, place of residence, smoking, marital status, obesity, economic index, and active workforce and LBP among Iranian men and women.

\section{Materials and Methods}

2.1. Data Set Examined. The National Health Survey in Iran (NHSI) is a survey designed to gain comprehensive knowledge and information about health care problems and difficulties in Iran. All necessary information for the conduct of this study was obtained from the NHSI database. These data were collected by the National Research Center of Medical Sciences and are presented partially at the Department of Biostatistics and Epidemiology, Tehran University of Medical Sciences for research. For the present study, pregnant women were excluded from the analyses, and the analyzed data included 25307 women and men aged 20-65 years. This study was approved by the Ethic Committee of the University of Social Welfare and Rehabilitation Sciences.

2.2. Study Outcome. Low back pain was defined as a binary variable with "yes" if a respondent has had low back trouble during the past 30 days.

\subsection{Personal Status Covariates}

Obesity. Height was measured in centimeters to the nearest $5 \mathrm{~mm}$ in a standing position, with shoes removed, using a wall-mounted stadiometer. Weight was measured to the nearest $0.1 \mathrm{~kg}$ with the subject in light indoor clothes, with shoes removed and emptied pockets. BMI (body mass index) was calculated as weight in kilograms divided by height in meters squared, and subjects were stratified into obese (BMI $\geq 30 \mathrm{~kg} / \mathrm{m}^{2}$ ) and nonobese $\left(\mathrm{BMI}<30 \mathrm{~kg} / \mathrm{m}^{2}\right)$.

Education Level. The respondents were categorized into three groups: those with low ( $0-8$ years), moderate (9-12 years), or high (more than 12 years) education.

Smoking. Smoking status was dichotomized into smoker versus nonsmoker.

Economic Index. Due to ethical considerations, we did not ask respondents about their income, because they were afraid of paying their taxes. We surrogated economic index for their household income. Economic index was defined as square meter of living place divided by number of household.

Demographic Variables. Information about the respondent's age was based on their self-reported birth year (age); females versus males based on (sex); married versus single based on (marital status); rural versus urban based on (place of residence).

2.4. Data Analysis. Descriptive statistics were presented in terms of prevalence of each covariate between subjects with and without LBP. We used $\chi^{2}$ tests to test significance of associations of each covariate with LBP. We applied logistic regressions to assess the association between obesity and LBP controlling for other covariates. In doing so, we first assessed a "crude" association between obesity and LBP without controlling for any variable. We then assessed the obesityLBP relationship after controlling for all other covariates. No statistical interactions between different covariates were detected. The results are presented as odds ratios and their 95\% confidence intervals (CI). The Hosmer-Lemeshow test was used in this model to evaluate the significance of improved port with introduction of additional variables. All analyses were carried out by using the SPSS software package, version 15.

\section{Results}

Our data included 25307 women and men aged 20-65 years with a mean age of 36.19 year. The presence of LBP was found in $29.3 \%$ of the respondents. The mean economic index was $23.62 \mathrm{~m}^{2}$. Of the respondents, $12.6 \%$ were obese, $56.2 \%$ were women and $34.4 \%$ were rural. Altogether, $14.1 \%$ and $80.6 \%$ were smoker and married, respectively. Overall, $25.5 \%$ and $8.2 \%$ of respondents were classified as moderate and high educational levels, respectively.

The prevalence of each covariate across the LBP categories is presented in Table 1. Results of $\chi^{2}$ tests showed that LBP was significantly associated with each of the covariates.

We started by fitting a preliminary logistic model including only obesity and LBP to observe the influence of the potential confounders on LBP. This model showed that unadjusted LBP odds ratio was 1.62 (95\% CI : 1.50-1.75).

In logistic model controlling for age, sex, economic index, education level, marital status, place of residence, and smoking status, adjusted LBP odds ratio was 1.15 (95\% CI: 1.06-1.24) for obesity. Comparing two models, we found that the LBP odds ratio decreased after adjustment for confounding variables, reducing by $47 \%$ from that of primary model. The results of the multivariate logistic model are shown in Table 2.

In the multivariate analysis, the presence of LBP was associated with the female gender. The LBP odds ratio was 3.05 (95\% CI : 2.84-3.27).

An association was observed between place of residence and LBP. The LBP odds ratio was 1.24 (95\% CI : 1.17-1.32) for rural participants. 
TABLE 1: Descriptive prevalence of low back pain across study variable levels.

\begin{tabular}{lccc}
\hline \multirow{2}{*}{ Variable } & \multicolumn{2}{c}{ Low back pain } & \multirow{2}{*}{ P value } \\
& No. & $\%$ & \\
Obesity & & & \\
$\quad$ Nonobese & 5209 & 28.0 & $<0.001$ \\
$\quad$ Obese & 1234 & 38.6 & \\
Sex & & & $<0.001$ \\
$\quad$ Men & 2162 & 18.3 & \\
$\quad$ Women & 5409 & 37.5 & $<0.001$ \\
Place of residence & & & \\
$\quad$ Urban & 4609 & 26.8 & $<0.001$ \\
$\quad$ Rural & 2962 & 32.6 & \\
Smoking & & & $<0.001$ \\
$\quad$ Smoker & 958 & 25.3 & \\
$\quad$ Nonsmoker & 6611 & 29.4 & \\
Marital status & & & \\
$\quad$ Single & 990 & 19.1 & \\
Married & 6581 & 31.2 & \\
Education level & & 33.9 & \\
$\quad$ Basic & 5898 & 20.2 & \\
Moderate & 1342 & 15.0 & \\
High & 324 & & \\
\hline
\end{tabular}

We found a statistically significant association between smoking and LBP. For smoker participants, the adjusted odds ratio was 1.40 (95\% CI : $1.27-1.53)$.

An association observed between marital status and LBP. The LBP odds ratio was 1.51 (95\% CI : 1.39-1.64) for married.

Overall, subjects with higher education appeared as an associated factors with OR less than 1. Using basic education as the reference group, LBP odds ratios were 0.79 (95\% CI: 0.73-0.85) and 0.65 (95\% CI: 0.57-0.74) for the moderate and high groups, respectively.

The Odds ratio of presence of LBP was inversely associated with the economic index. The LBP odds ratio was 0.996 (95 percent CI: $0.994-0.998)$. A $1-\mathrm{m}^{2}$ increase in economic index has $1 \%$ decrease in the odds of LBP.

The odds of presence of LBP increased with age. The LBP odds ratio was 1.03 (95 percent CI : 1.029-1.034). We infer that a 1 -year increase in age has $3 \%$ increase in the odds of LBP.

\section{Discussion}

In this cross-sectional study, we assessed associations between the some factors and presence of LBP in men and women. In the first model (without confounders), unadjusted LBP ratio was 1.62 (95\% CI : 1.50-1.75). Furthermore, we adjusted the odds ratio for common known covariates for LBP, for example, smoking and sociodemographic factors. After adjustment for confounding variables, obesity is positively associated with presence of LBP in adults.
TABLe 2: Adjusted ${ }^{\mathrm{a}}$ odds ratios for low back pain among 25307 Iranian adults, National Health Survey in Iran, in the logistic analysis.

\begin{tabular}{|c|c|c|}
\hline variable & $\mathrm{OR}^{\mathrm{b}}$ & $95 \% \mathrm{CI}^{\mathrm{c}}$ \\
\hline \multicolumn{3}{|l|}{ Obesity } \\
\hline Nonobese & 1.00 & \\
\hline Obese & 1.15 & $1.06-1.24$ \\
\hline \multicolumn{3}{|l|}{ Sex } \\
\hline Men & 1.00 & \\
\hline Women & 3.05 & $2.84-3.27$ \\
\hline \multicolumn{3}{|c|}{ Place of residence } \\
\hline Urban & 1.00 & \\
\hline Rural & 1.24 & $1.17-1.32$ \\
\hline \multicolumn{3}{|l|}{ Smoking } \\
\hline Nonsmoker & 1.00 & \\
\hline Smoker & 1.40 & $1.27-1.53$ \\
\hline \multicolumn{3}{|l|}{ Marital status } \\
\hline Single & 1.00 & \\
\hline Married & 1.51 & $1.39-1.64$ \\
\hline \multicolumn{3}{|l|}{ Education level } \\
\hline Basic & 1.00 & \\
\hline Moderate & 0.79 & $0.73-0.85$ \\
\hline High & 0.65 & $0.57-0.74$ \\
\hline Economy index & 0.996 & $0.994-0.998$ \\
\hline Age & 1.03 & $1.029-1.034$ \\
\hline
\end{tabular}

adjusted for all other variables in the table.

${ }^{\mathrm{b}}$ Odds ratio.

${ }^{\mathrm{c} C o n f i d e n c e ~ i n t e r v a l . ~}$

Obesity behaved as an important predictor in two models, in agreement with the findings in the literature [30$32,1,24]$. Shiri et al. have reported that obesity is a risk factor for LBP in both cross-sectional and cohort studies [24]. Biomechanic and metabolic factors have been suggested to explain this relation. Obesity may cause LBP through metabolic syndrome. it is also possible that obesity and low back pain would be linked more directly via inflammatory mechanisms [35]. One study showed that people with high BMI increased risk of injury as well as higher injury-related expenditure [36]. Obesity has been shown as a risk factor for disc degeneration [37] and may increase the prevalence of LBP from this way. Because of a worldwide increase in the prevalence of obesity [14], it is reasonable to assume that the prevalence of back pain will continue to increase.

Studies have shown that the prevalence of LBP in the general population was higher in women than in men, and these findings are in agreement with the results of the present sample $[2,10,21-24]$. The sex difference could be related to gonadal steroid hormones such as estradiol and testosterone modulate sensitivity to pain and analgesia [38]. It is possible that LBP would have more influence on the life style habits in females than in males. Other variables such as diet, parity, and use of contraceptives may be relevant.

Rural people had higher prevalence of LBP than urban people. We conclude that the geographical variation in 
prevalence of LBP in Iran is largely due to differences in propensity to consult a doctor once a symptom is present, and patient behaviour once symptoms have developed. Our results are consistent with some studies that reported the regional differences in the prevalence of LBP $[29,39]$.

In agreement with earlier findings $[7,25,26,28]$, our results showed that smoking, consistently associated with LBP. The association between smoking and LBP may be explained by the analgesic properties of nicotine [40]. Smokers might have stopped smoking on doctors' orders due to some disease that could be related to pain [41]. Smoking can effect on disc height [42]. Some biologically plausible explanations could be related to the effect of smoking on nutrition of the disc [43]. A positive correlation between severe disk degeneration and LBP was found in some studies [44].

Compared with unmarried, significantly increased odds of LBP were seen in married participants. Our results are consistent with some studies [45]. It is possible that the presence of a spouse may operate as a social factor on lack of LBP. It may include physiological mechanisms after their marriage.

According to the literature, people with lower educational attainment and economic index have an increased prevalence of LBP [3, 26-29]. These findings were also apparent among our participants.

There are likely to be other aspects of environments and lifestyle which influence the presence of LBP.

It is possible that LBP is more likely to be reported by those with lower economic index and lower educational qualification. Higher education and economy may provide knowledge or resource thet influences on the lack of LBP.

Our findings suggest that age was an important associated factor revealing that prevalence of LBP increases with the increase of age. Age has also been a strong predictor for LBP in some previous studies $[19,20]$, possibly due to increasing degeneration of the tendons resulting from aging.

There are several limitations in this study. The analysis is cross-sectional and therefore unable to infer causation. We did not examine all potentially important variables. Marital status could be categorized into legally married and nonmarried only. Nonmarried people are a very heterogeneous group and should be more closely examined in further studies. The lack of approach to the functional impairment is a limitation to this study. The chronic pain is also not included in our investigation. Although we cannot be certain of the temporal relationship between these variables and LBP, any of these can influence and limit the inferences about factors associated with LBP in this sample.

Despite these limitations, the NHS sampling design permits the representative sampling of households in Iran. The adult respondents included in this paper are therefore a valid representative sample of the Iranian population ages 20 years and older. Height and weight were actually measured rather than self-reported. It is well known that self-reports underestimate the prevalence of obesity.

\section{Conclusion}

Our findings add to the evidence on the importance of obesity in relation to low back pain. If confirmed in other studies, these findings will have implications with respect to attempts in preventing obesity in the population.

\section{Conflict of Interests}

The authors have no conflict of interests.

\section{Acknowledgments}

This study was financed by a grant from Tehran University of Medical Science \& Health Services. The authors acknowledge the National Health Survey for their data, coordinated at the Department of Biostatistics, School of Public Health and Institute of Public Health Research, Tehran University of Medical Science, Iran.

\section{References}

[1] T. W. Strine and J. M. Hootman, "US national prevalence and correlates of low back and neck pain among adults," Arthritis Care and Research, vol. 57, no. 4, pp. 656-665, 2007.

[2] R. Shiri, S. Solovieva, K. Husgafvel-Pursiainen et al., "The association between obesity and the prevalence of low back pain in young adults: the cardiovascular risk in young finns study," American Journal of Epidemiology, vol. 167, no. 9, pp. 1110-1119, 2008.

[3] R. Webb, T. Brammah, M. Lunt, M. Urwin, T. Allison, and D. Symmons, "Prevalence and predictors of intense, chronic, and disabling neck and back pain in the UK general population," Spine, vol. 28, no. 11, pp. 1195-1202, 2003.

[4] W. J. Meerding, W. IJzelenberg, M. A. Koopmanschap, J. L. Severens, and A. Burdorf, "Health problems lead to considerable productivity loss at work among workers with high physical load jobs," Journal of Clinical Epidemiology, vol. 58, no. 5, pp. 517-523, 2005.

[5] J. D. Cassidy, L. J. Carroll, and P. Côté, "The Saskatchewan health and back pain survey: the prevalence of low back pain and related disability in Saskatchewan adults," Spine, vol. 23, no. 17, pp. 1860-1867, 1998.

[6] R. Waxman, A. Tennant, and P. Helliwell, "A prospective follow-up study of low back pain in the community," Spine, vol. 25, no. 16, pp. 2085-2090, 2000.

[7] M. Harreby, J. Kjer, G. Hesselsøe, and K. Neergaard, "Epidemiological aspects and risk factors for low back pain in 38-yearold men and women: a 25-year prospective cohort study of 640 school children," European Spine Journal, vol. 5, no. 5, pp. 312-318, 1996.

[8] M. Heliovaara, K. Sievers, O. Impivaara et al., "Descriptive epidemiology and public health aspects of low back pain," Annals of Medicine, vol. 21, no. 5, pp. 327-333, 1989.

[9] G. B. J. Andersson, "Epidemiological features of chronic lowback pain,” The Lancet, vol. 354, no. 9178, pp. 581-585, 1999.

[10] J. McBeth and K. Jones, "Epidemiology of chronic musculoskeletal pain," Best Practice and Research, vol. 21, no. 3, pp. 403-425, 2007.

[11] Q. A. Louw, L. D. Morris, and K. Grimmer-Somers, "The prevalence of low back pain in Africa: a systematic review," BMC Musculoskeletal Disorders, vol. 8, article 105, 2007. 
[12] E. Bakhshi, B. Seifi, A. Biglarian, and K. Mohammad, "Changes in body mass index across age groups in iranian women: results from the national health survey," Journal of Nutrition and Metabolism, vol. 2012, Article ID 848403, 9 pages, 2012.

[13] M. de Onis, M. Blössner, and E. Borghi, "Global prevalence and trends of overweight and obesity among preschool children," American Journal of Clinical Nutrition, vol. 92, no. 5, pp. 1257-1264, 2010.

[14] J. C. Seidell, "Epidemiology of obesity," Seminars in Vascular Medicine, vol. 5, no. 1, pp. 3-14, 2005.

[15] T. J. Mielenz, R. F. Devellis, M. C. Battie, and T. S. Carey, "Stop using the modified work APGAR to measure job satisfaction," Pain Research and Treatment, vol. 2011, Article ID 406235, 8 pages, 2011.

[16] M. K. Nicholas, S. J. Linton, P. J. Watson, C. J. Main, and Decade of the Flags Working Group, "Early identification and management of psychological risk factors ("yellow flags") in patients with low back pain: a reappraisal," Physical Therapy, vol. 91, no. 5, pp. 737-753, 2011.

[17] T. Pincus, J. W. Vlaeyen, N. A. Kendall, M. R. Von Korff, D. A. Kalauokalani, and S. Reis, "Cognitive-behavioral therapy and psychosocial factors in low back pain: directions for the future," Spine, vol. 27, no. 5, pp. E133-E138, 2002.

[18] R. A. Williams, S. D. Pruitt, J. N. Doctor et al., "The contribution of job satisfaction to the transition from acute to chronic low back pain," Archives of Physical Medicine and Rehabilitation, vol. 79, no. 4, pp. 366-374, 1998.

[19] A. Bener, R. Alwash, T. Gaber, and G. Lovasz, "Obesity and low back pain," Collegium Antropologicum, vol. 27, no. 1, pp. 95-104, 2003.

[20] D. D. Ouédraogo, V. Ouédraogo, L. T. Ouédraogo et al., "Prevalence and factors associated with low back pain among hospital staff in Ouagadougou (Burkina Faso)," Médecine Tropicale, vol. 70, no. 3, pp. 277-280, 2010.

[21] S. Schneider, D. Randoll, and M. Buchner, "Why do women have back pain more than men? A representative prevalence study in the Federal Republic of Germany," Clinical Journal of Pain, vol. 22, no. 8, pp. 738-747, 2006.

[22] H. A. H. Wijnhoven, H. C. W. de Vet, and H. S. J. Picavet, "Prevalence of musculoskeletal disorders is systematically higher in women than in men," Clinical Journal of Pain, vol. 22, no. 8, pp. 717-724, 2006.

[23] P. Hakala, A. Rimpelä, J. J. Salminen, S. M. Virtanen, and M. Rimpelä, "Back, neck, and shoulder pain in Finnish adolescents: national cross sectional surveys," British Medical Journal, vol. 325, no. 7367, pp. 743-745, 2002.

[24] R. Shiri, J. Karppinen, P. Leino-Arjas, S. Solovieva, and E. Viikari-Juntura, "The association between obesity and low back pain: a meta-analysis," American Journal of Epidemiology, vol. 171, no. 2, pp. 135-154, 2010.

[25] F. Biering-Sorensen and C. Thomsen, "Medical, social and occupational history as risk indicators for low-back trouble in a general population," Spine, vol. 11, no. 7, pp. 720-725, 1986.

[26] P. R. Croft and A. S. Rigby, "Socioeconomic influences on back problems in the community in Britain," Journal of Epidemiology and Community Health, vol. 48, no. 2, pp. 166170, 1994.

[27] J. W. Frymoyer, M. H. Pope, M. C. Costanza, J. C. Rosen, J. E. Goggin, and D. G. Wilder, "Epidemiologic studies of low-back pain," Spine, vol. 5, no. 5, pp. 419-423, 1980.

[28] C. F. Müller, T. Monrad, F. Biering-Sørensen, E. Darre, A. Deis, and P. Kryger, "The influence of previous low back trouble, general health, and working conditions on future sick-listing because of low back trouble: a 15-year follow-up study of risk indicators for self-reported sick-listing caused by low back trouble," Spine, vol. 24, no. 15, pp. 1562-1570, 1999.

[29] R. A. Deyo and Y. J. Tsui-Wu, "Descriptive epidemiology of low-back pain and its related medical care in the United States," Spine, vol. 12, no. 3, pp. 264-268, 1987.

[30] R. A. Deyo and J. E. Bass, "Lifestyle and low-back pain. The influence of smoking and obesity," Spine, vol. 14, no. 5, pp. 501-506, 1989.

[31] J. K. Lake, C. Power, and T. J. Cole, "Back pain and obesity in the 1958 British birth cohortcause or effect?" Journal of Clinical Epidemiology, vol. 53, no. 3, pp. 245-250, 2000.

[32] I. Heuch, K. Hagen, I. Heuch, O. Nygaard, and J. A. Zwart, "The impact of body mass index on the prevalence of low back pain: the HUNT study," Spine, vol. 35, no. 7, pp. 764$768,2010$.

[33] M. Heliovaara, M. Makela, P. Knekt, O. Impivaara, and A. Aromaa, "Determinants of sciatica and low-back pain," Spine, vol. 16, no. 6, pp. 608-614, 1991.

[34] C. Power, J. Frank, C. Hertzman, G. Schierhout, and L. Li, "Predictors of low back pain onset in a prospective British study," American Journal of Public Health, vol. 91, no. 10, pp. 1671-1678, 2001.

[35] H. Tilg and A. R. Moschen, "Adipocytokines: mediators linking adipose tissue, inflammation and immunity," Nature Reviews Immunology, vol. 6, no. 10, pp. 772-783, 2006.

[36] H. Y. Hu, Y. J. Chou, P. Chou, L. K. Chen, and N. Huang, "Association between obesity and injury among Taiwanese adults," International Journal of Obesity, vol. 33, no. 8, pp. 878884, 2009.

[37] M. Liuke, S. Solovieva, A. Lamminen et al., "Disc degeneration of the lumbar spine in relation to overweight," International Journal of Obesity, vol. 29, no. 8, pp. 903-908, 2005.

[38] R. M. Craft, J. S. Mogil, and A. M. Aloisi, "Sex differences in pain and analgesia: the role of gonadal hormones," European Journal of Pain, vol. 8, no. 5, pp. 397-411, 2004.

[39] A. Bjelle and E. Allander, "Regional distribution of rheumatic complaints in Sweden," Scandinavian Journal of Rheumatology, vol. 10, no. 1, pp. 9-15, 1981.

[40] D. A. Fishbain, B. Cole, R. B. Cutler, J. Lewis, H. L. Rosomoff, and R. S. Rosomoff, "Is pain fatiguing? A structured evidencebased review," Pain Medicine, vol. 4, no. 1, pp. 51-62, 2003.

[41] K. N. Sá, A. F. Baptista, M. A. Matos, and I. Lessa, "Chronic pain and gender in Salvador population, Brazil," Pain, vol. 139, no. 3, pp. 498-506, 2008.

[42] M. C. Battie, T. Videman, K. Gill et al., "1991 Volvo award in clinical sciences: smoking and lumbar intervertebral disc degeneration: an MRI study of identical twins," Spine, vol. 16, no. 9, pp. 1015-1021, 1991.

[43] E. Ernst, "Smoking, a cause of back trouble?" British Journal of Rheumatology, vol. 32, no. 3, pp. 239-242, 1993.

[44] K. M. C. Cheung, J. Karppinen, D. Chan et al., "Prevalence and pattern of lumbar magnetic resonance imaging changes in a population study of one thousand forty-three individuals," Spine, vol. 34, no. 9, pp. 934-940, 2009.

[45] J. Knox, J. Orchowski, D. L. Scher, B. D. Owens, R. Burks, and P. J. Belmont, "The incidence of low back pain in active duty United States military service members," Spine, vol. 36, no. 18, pp. 1492-1500. 


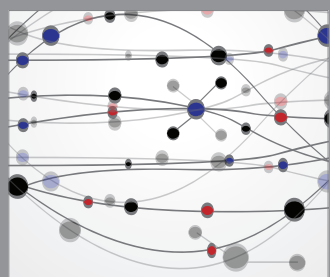

The Scientific World Journal
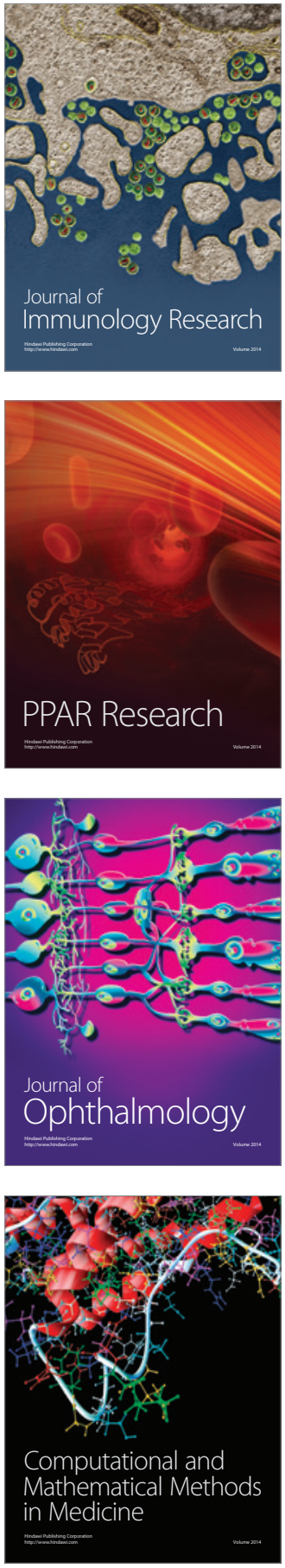

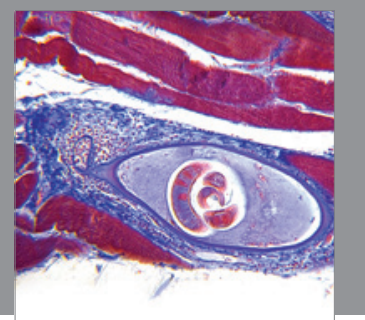

Gastroenterology

Research and Practice
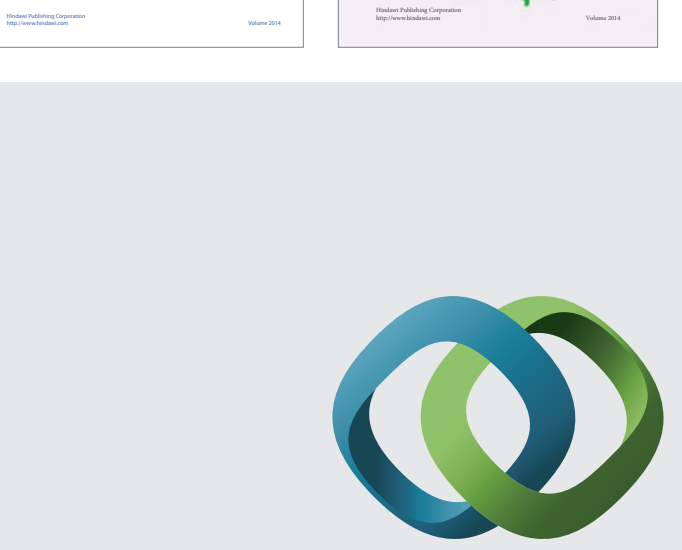

\section{Hindawi}

Submit your manuscripts at

http://www.hindawi.com
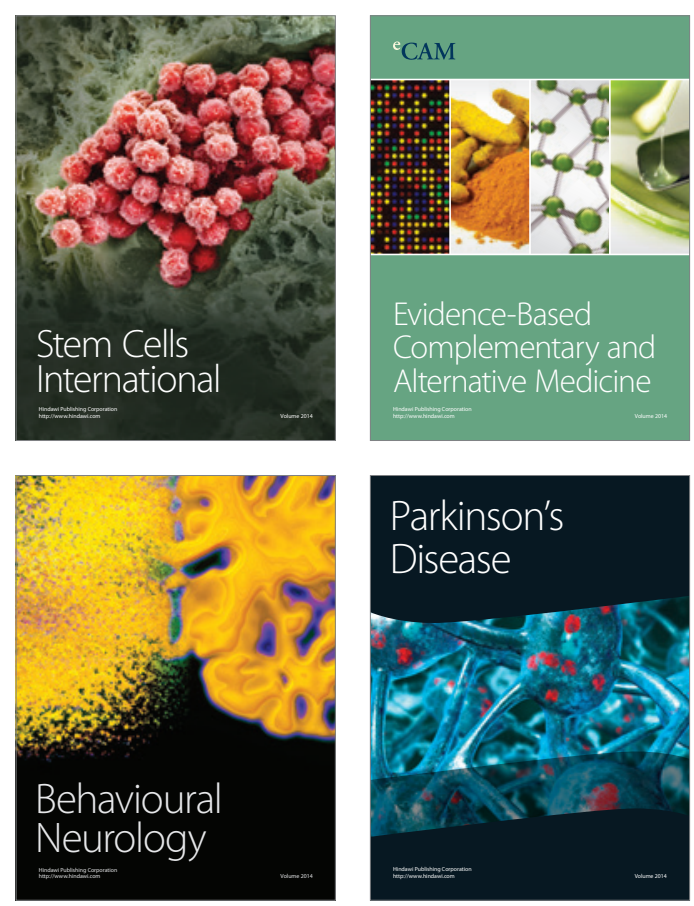

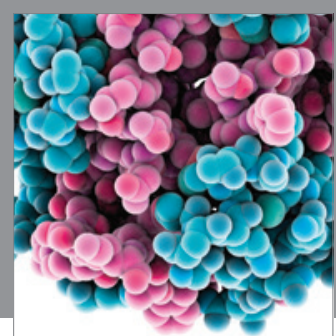

Journal of
Diabetes Research

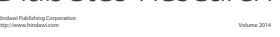

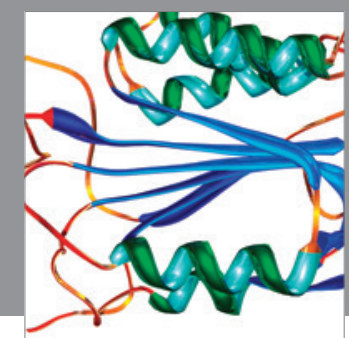

Disease Markers
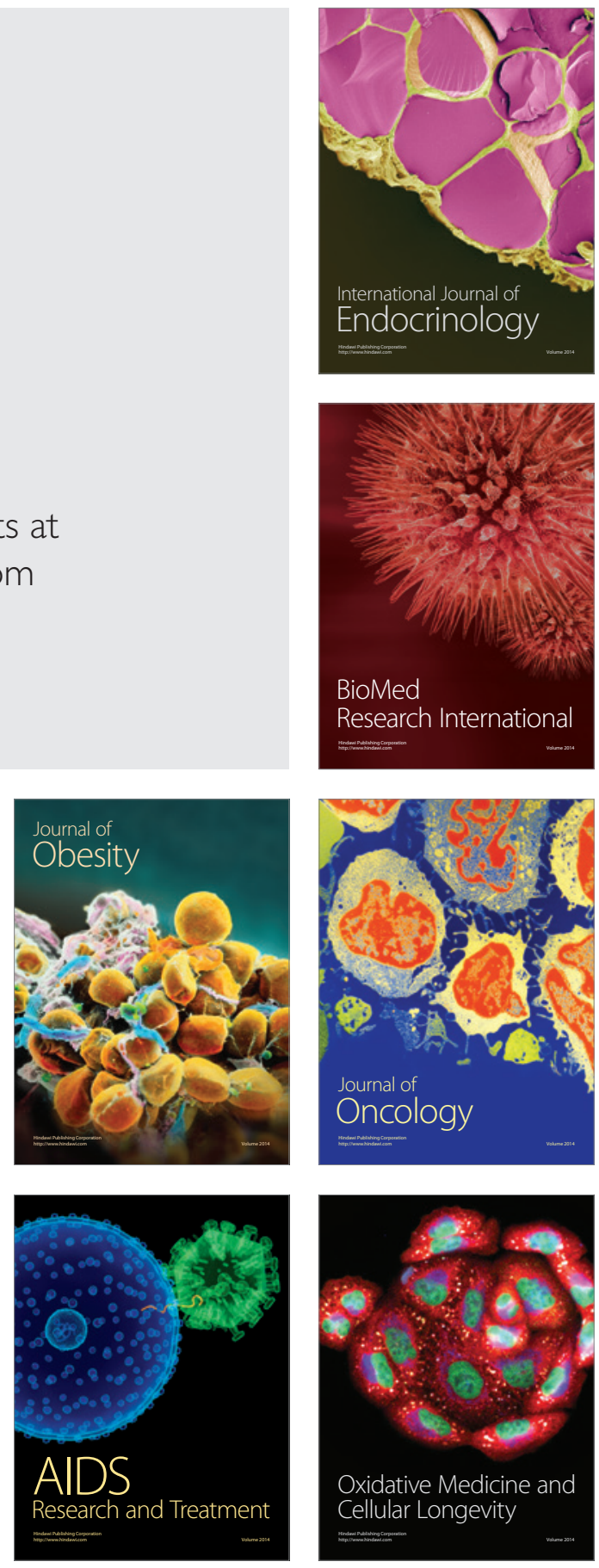